results of this test on a normal population have apparently not been reported in detail.

The incidence of treatment for depression in these patients corresponded closely with that found in other series ${ }^{5}$; such treatment is most commonly given to neurotic patients, who appear to be more concerned about the course of their disease.

A startling finding was the number of patients who felt that their illness had improved their marital relationship. It was a recurrent theme that illness had drawn them closer together and increased mutual understanding. Sexual activity was a noticeable exception to this. Diminished sex drive has also been recorded in other chronic illnesses. ${ }^{6}$ In a study of Crohn's disease Ford et al found no major sexual problems but noted that their patients were "comparatively uninterested in sexual relationships." ; Many of our patients were unable to relax because of the fear of diarrhoea or abdominal pain, and in those marriages that had become less happy sexual dissatisfaction was nearly always the root cause.

Crohn's disease is a frightening diagnosis for both patient and doctor, with the prospect of chronic illness and acute exacerbations over many years and a death rate above that of the general population. ${ }^{8}$ Obviously the patient experiences considerable apprehension about his role in the family and at work, and the possibility of death. Thus interpersonal relationships will change at a time when the patient most needs them. Under these circumstances some degree of psychological regression is common, and patients with a poor premorbid psychological make-up-that is, who are neurotic-are likely to adapt badly.

This survey shows that the most important determinant of a patient's prospects is not the extent or activity of his disease but his personality, and underlines the truth of the old medical aphorism that the whole patient should be treated rather than the disease alone. Furthermore, it highlights some of the difficulties in using symptoms to assess disease activity when comparing the efficiency of various treatment regimens.

\section{References}

${ }^{1}$ Salkind, M R, Postgraduate Medical fournal, 1972, 5, 34.

2 Eysenck, H G, and Eysenck, S B G, Manual of the Eysenck Personality Questionnaire. London, Hodder and Stoughton, 1977.

3 Willoughby, J M T, et al, Lancet, 1971, 2, 944.

${ }^{4}$ Sheffield, B F, and Carney, M W P, British fournal of Psychiatry, 1976, 128, 446.

5 Whybrow, P C, and Ferrell, R B, in Emotional Factors in Gastrointestinal Illness, ed A E Lindner, p 82. Amsterdam, Excerpta Medica Foundation, 1973.

${ }^{6}$ Levy, N B, and Wynbrandt, G D, Lancet, 1975, 1, 1328.

7 Ford, C V, Glober, G A, and Castelnuovo-Tedesco, P, fournal of the American Medical Association, 1969, 208, 311.

8 Truelove, S G, and Pena, A S, Gut, 1976, 17, 192.

\title{
Respiratory distress syndrome in infants of Cardiff residents during 1965-75
}

\author{
IAIN CHALMERS, M E DAUNCEY, E R VERRIER-JONES, J A DODGE, O P GRAY
}

British Medical fournal, 1978, 2, 1119-1121

\section{Summary and conclusions}

The incidence of respiratory distress syndrome (RDS) among singleton infants of Cardiff residents was greater during 1970-4 than in the preceding five years. This was consistent with changes in the distribution of gestational age and birth weight. Case fatality rates among infants with RDS fell only slightly during the period examined.

Detailed examination of secular trends during 1965-75 suggested $(a)$ that increased use of elective delivery without assessment of pulmonary maturity increases the risk of RDS, and (b) that innovations in the management of RDS during the early 1970s cannot be assumed to have had widespread impact on case fatality rates.

\section{Introduction}

Respiratory distress syndrome (RDS) remains a major cause of neonatal morbidity ${ }^{1}$ and mortality ${ }^{2}$ despite developments in its

Welsh National School of Medicine, Cardiff CF4 4XN

IAIN CHALMERS, DCH, MRCOG, MRC research fellow, department of medical statistics (present address: National Perinatal Epidemiology Unit, Research Institute, Churchill Hospital, Oxford OX3 7LJ)

M E DAUNCEY, BA, computer programmer, department of medical statistics

E R VERRIER-JONES, DCH, FRCPED, consultant paediatrician

J A DODGE, MD, FRCPED, reader in child health

O P GRAY, DCH, FRCP, professor of child health prevention ${ }^{3-5}$ and treatment. ${ }^{6}$ In assessing the incidence of the syndrome, however, several difficulties arise. The first is in definition: RDS is a clinical diagnosis that may subsume one or more various pathological states, some of which may be confirmed only by necropsy. Although neonatal paediatricians in Switzerland ${ }^{1}$ and Sweden ${ }^{7}$ have agreed on diagnostic criteria for incidence studies, the diagnosis of RDS elsewhere continues to imply different things to different people. An additional problem is the lack of data on total populations of neonates. Most published studies refer to hospital case loads and may therefore distort true incidence rates. We know of only two published incidence studies referring to total populations of neonates, ${ }^{18}$ and only one of these examined secular trends in the incidence of RDS. ${ }^{8}$

Knowing current trends in the incidence of RDS seems important in view of the increasing number of reports of iatrogenic RDS after elective delivery. ${ }^{9-12}$ We decided to examine the incidence of RDS in Cardiff after observing that birth weight and gestational age distributions had "shifted to the left" during 1965-74. ${ }^{13}$ We were unable to explain this phenomenon by changes in maternal age, parity, height, smoking habits, or history of abortion and think that it may have resulted from increased use of elective delivery during 1969-72. We report here changes in the incidence of RDS and neonatal mortality rates attributed to the syndrome among infants born to Cardiff residents between 1965 and 1975.

\section{Materials and methods}

Since 1965 the Cardiff Births Survey has provided perinatal data on all deliveries to Cardiff residents regardless of where delivery takes place. All infants are followed up until the 28th day after birth, 
when data collection stops. We used the Cardiff Births Survey to document changes in the incidence and outcome of RDS and certain other conditions causing neonatal morbidity and mortality.

RDS is more common after multiple pregnancy. Cardiff has experienced a decline in multiple births, ${ }^{14}$ so our analysis is confined to singleton liveborn infants of Cardiff residents. Because the incidence of many of the variables examined was so low we compared the experience of 22456 infants born alive during 1965-9 with 19524 infants born during 1970-4. In certain instances, however, we examined trends in yearly rates from 1965 to 1975 . Data on length of stay in special-care units were derived from Hospital Activity Analysis. The $\chi^{2}$ test was used to examine differences in proportions, and Student's $t$ test to examine differences between mean values.

\section{Results}

CHARACTERISTICS OF NEONATAL POPULATION

We have already described changes in the parturient and infant populations in Cardiff. ${ }^{13}{ }^{15}$ The change most relevant to neonatal practice is the shift in the distributions of birth weight and gestational age (fig 1). We showed that these differences persist after controlling for changes in maternal age, parity, height, smoking habits, and history of abortion. ${ }^{13}$ When all singleton liveborn infants were considered there were $23 \%$ more infants born at 34 and 35 completed weeks of gestation during 1970-4 than would have been expected from the incidence during 1965-9. These changes were reflected in an $18 \%$ excess over expectation in the proportion born weighing 2000$2499 \mathrm{~g}$ during the second quinquennium.

\section{NEONATAL MORTALITY AND MORBIDITY}

There was a significant fall in the overall neonatal death rate between 1965-9 and 1970-4 $(P<0.025)$, mostly due to fewer deaths from congenital abnormality (table I). There was no measurable change in death rates from RDS or other causes associated with immaturity. Table II compares the neonatal morbidity rates in the two quinquennia. The incidence of RDS increased from 11.9/1000 live births to $13 \cdot 4 / 1000$, but this difference does not reach conventional levels of significance. The incidence of intracranial haemorrhage (which includes intraventricular haemorrhage) increased from $2 \cdot 4 / 1000$ to $3.8 / 1000$, which is significant at the $5 \%$ level. Of the other diagnostic groups examined, only congenital abnormality showed a significant change in incidence-from $22 \cdot 6$ to $25 \cdot 7 / 1000$ live births $(P<0 \cdot 05)$.

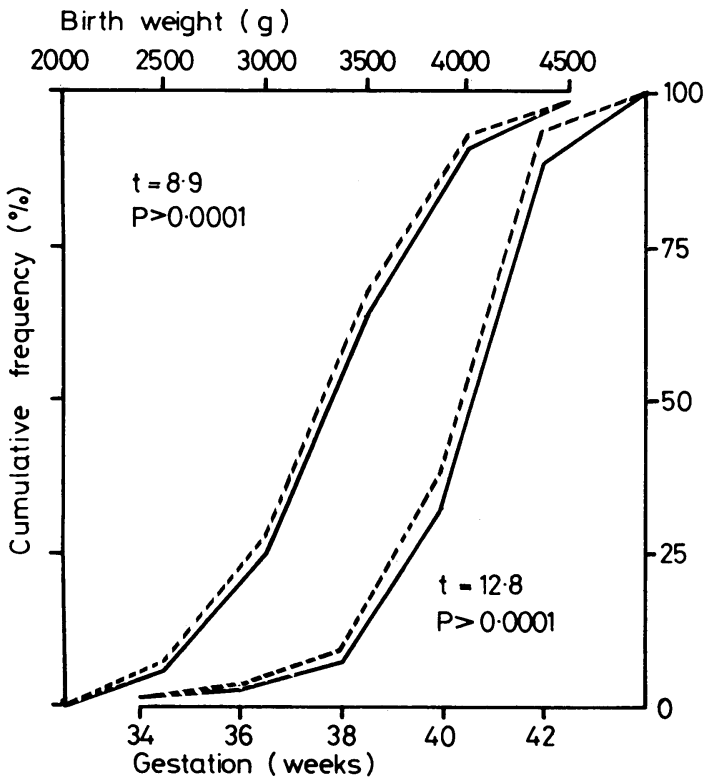

FIG 1-Cumulative frequency distributions of birth weight and completed weeks of gestation of singleton infants born alive to Cardiff residents during 1965-9 (-) and 1970-4 (----).
TABLE I-Neonatal mortality rates (per 1000 live births) and primary causes of death among singleton infants born to Cardiff residents during 1965-9 and $1970-4$

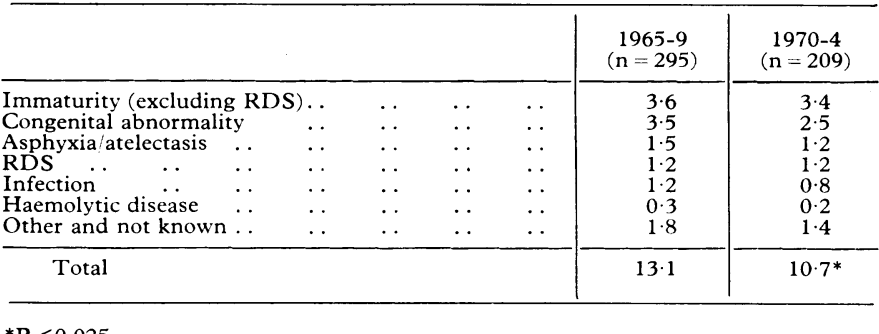

TABLE II-Neonatal morbidity rates (per 1000 live births) among singleton infants born to Cardiff residents during 1965-9 and 1970-4

\begin{tabular}{|c|c|c|c|c|c|c|}
\hline & & & & & $\begin{array}{c}1965-9 \\
(\mathrm{n}=22456)\end{array}$ & $\begin{array}{c}1970-4 \\
(\mathrm{n}=19524)\end{array}$ \\
\hline Congenital abnormality & . & . & . & . & $22 \cdot 6$ & $25 \cdot 7 *$ \\
\hline Systemic infection $\quad$. & . & .. & .. & . & $13 \cdot 1$ & $13 \cdot 1$ \\
\hline RDS $\because$ & . & .. & 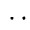 & .. & 11.9 & $13 \cdot 4$ \\
\hline Intracranial haemorrhage & $\ldots$ & .. & .. & . & $2 \cdot 4$ & $3.8^{*}$ \\
\hline Haemolytic disease $\quad \ldots$ & . & .. & . & . & $5 \cdot 5$ & 6.5 \\
\hline Haemorrhagic disease .. & . & .. & .. & .. & $0 \cdot 80$ & $0 \cdot 87$ \\
\hline
\end{tabular}

$* \mathrm{P}<0 \cdot 05$.

Figure 2 plots the yearly incidences of RDS, depressed Apgar scores $(<8)$, elective delivery (induction of labour and elective caesarean section), and intrapartum fetal blood sampling during 1965-75. The incidence of RDS declined slightly during 1965-7 then rose sharply to a plateau of about $15 / 1000$, which was maintained over the next five years. In 1972 the rate began to decline rapidly, reaching its lowest recorded level $(7 \cdot 7 / 1000)$ in 1975 . This decline was accompanied by a fall in the incidence of depressed Apgar scores, which until 1972 had steadily increased. The falling incidence of RDS and depressed Apgar scores during 1972-5 coincided with important changes in obstetric practice (fig 2 ). The incidence of elective delivery declined due to an altered approach to the induction of labour ${ }^{16}$; increased use was made of acid-base assessment of the fetus during labour ${ }^{17}$; and assays were introduced to predict neonatal pulmonary maturity with greater precision. ${ }^{4}$

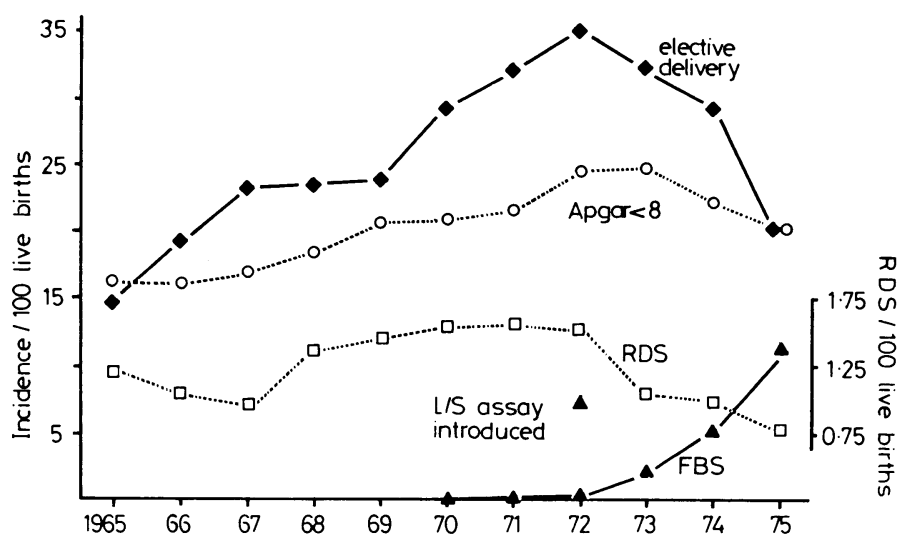

FIG 2-Incidences (per 100 live births) of elective delivery, low Apgar scores $(<8)$, and fetal blood sampling (FBS) and of RDS (per 100 live births) among liveborn infants of Cardiff residents during 1965-75. L/S assay $=$ Introduction of amniotic phospholipid assay as measure of surfactant in fetal lungs.

\section{NEONATAL MANAGEMENT}

Methods of resuscitation changed in Cardiff during the study period. Endotracheal intubation was used in $2.5 \%$ of infants born during 1965-7 and then fell to half that level in 1968, when positive-pressure ventilation using a facemask (the Cardiff bag) was introduced on a wider scale. The use of intubation continued to decline until 1972 , by which time the Cardiff bag was being used in $15 \%$ of neonates. 
TABLE III-Use of special-care unit for infants born alive to mothers resident in Cardiff during 1965-74

\begin{tabular}{|c|c|c|c|c|c|c|c|c|c|c|c|c|c|c|c|}
\hline & & & & & & 1965 & 66 & 67 & 68 & 69 & 70 & 71 & 72 & 73 & 74 \\
\hline $\begin{array}{l}\text { No of admissions } \ldots \\
\text { Percentage of all live births } \\
\text { Percentage with birth weight } \geqslant 2500 \mathrm{~g} \\
\text { Average length of stay* (days) }\end{array}$ & $\begin{array}{l}\cdots \\
\cdots \\
\cdots\end{array}$ & $\begin{array}{l}\ldots \\
\cdots \\
\cdots\end{array}$ & $\begin{array}{l}\cdots \\
\cdots \\
\cdots\end{array}$ & $\begin{array}{l}\cdots \\
\cdots \\
\cdots\end{array}$ & $\begin{array}{l}\ldots \\
\cdots \\
\cdots\end{array}$ & $\begin{array}{l}247 \\
5 \cdot 2 \\
40 \cdot 9 \\
\text { NA }\end{array}$ & $\begin{array}{l}282 \\
6 \cdot 1 \\
44 \cdot 0 \\
\mathrm{NA}\end{array}$ & $\begin{array}{r}279 \\
6 \cdot 3 \\
40 \cdot 9 \\
\text { NA }\end{array}$ & $\begin{array}{r}333 \\
7 \cdot 1 \\
44 \cdot 7 \\
\mathrm{NA}\end{array}$ & $\begin{array}{r}316 \\
7 \cdot 2 \\
47 \cdot 8 \\
15 \cdot 8\end{array}$ & $\begin{array}{r}385 \\
9 \cdot 0 \\
42 \cdot 9 \\
15 \cdot 2\end{array}$ & $\begin{array}{r}393 \\
9 \cdot 2 \\
50 \cdot 4 \\
12 \cdot 1\end{array}$ & $\begin{array}{r}485 \\
12 \cdot 2 \\
56 \cdot 7 \\
11 \cdot 7\end{array}$ & $\begin{array}{r}502 \\
13 \cdot 5 \\
62 \cdot 0 \\
8 \cdot 3\end{array}$ & $\begin{array}{r}642 \\
17 \cdot 7 \\
67 \cdot 8 \\
5 \cdot 0\end{array}$ \\
\hline
\end{tabular}

*From Hospital Activity Analysis data relating to St David's Hospital, Cardiff, only.

NA $=$ Not assessed.

After 1972 these trends reversed. Admission rates to special-care baby units increased in line with national experience ${ }^{18}$ (table III), mature infants accounting for the trend in Cardiff.

Continuous positive airway pressure (CPAP) ventilation was introduced in Cardiff in 1972 and had become established practice by 1973. Case fatality rates from RDS fell slightly from $10 \cdot 1 \%$ during $1965-9$ to $9.0 \%$ during 1970-4. Pneumothorax or interstitial emphysema occurred in two out of 129 cases of RDS in 1970-1, eight out of 97 cases in 1972-3, and one out of 60 cases in 1974-5. Seven of the eight cases of pneumothorax in 1972-3 occurred in babies not given CPAP.

\section{Discussion}

Our data were derived from a total population. The rates presented are therefore more likely to reflect true incidences than those based on hospital populations. We emphasise again, however, the difficulties entailed in interpretation. Firstly, although we believe our mortality data to be accurate, the few deaths, even in a population this large, constrain our interpretation of the rates we have calculated. Secondly, although morbidity statistics may furnish larger numerators, the nature of the data presents other problems. Although the coding rules of the Cardiff Births Survey have remained largely unchanged since its inception, subtle changes in diagnostic practice may have occurred. For example, in an earlier report $^{15}$ we noted that an observed increase in fetal distress in our population may have resulted from more frequent or continuous fetal heart rate monitoring at a time when the management of labour in hospital was becoming more common. We share these difficulties with anyone who analyses data that have been collected over an extended period, but we nevertheless think that our study contributes useful information on both the aetiology and management of RDS.

Our finding of an increased incidence of RDS during a period when elective delivery was more common is consistent both with our findings in respect of birth weight and gestational age distributions in neonates, ${ }^{13}$ and also the published reports of inadvertent premature delivery after elective induction and caesarean section, and the increasing incidence of RDS elsewhere. ${ }^{8}$ Trends in the yearly incidence rates for RDS in Cardiff also support the hypothesis, in that these fell during 1972-5 as elective delivery became less common. Amniotic phospholipid assay was available in Cardiff at the beginning of this period, ${ }^{4}$ which almost certainly contributed to a reduced risk of RDS among the declining numbers of neonates delivered electively.

Another factor that may have promoted the decline in RDS was the fall in the incidence of depressed Apgar scores. We cannot be certain what caused this trend. It occurred during a period when induction of labour was becoming less frequent, intensive intrapartum fetal monitoring was introduced, and caesarean section was becoming more common. There is no experimentally derived evidence that any of these trends are causally linked except the last two. ${ }^{19} 20$

Another feature of our data concerns the slight fall in the case fatality rate from RDS over a period when new approaches to the management of RDS, and small babies in general, were introduced. We believe that these findings are consistent with the relatively small effects on mortality from hyaline membrane disease shown in early trials of CPAP. ${ }^{21}$ Subsequent developments, ${ }^{22}$ however, suggest that starting CPAP treatment earlier in the disease may lead to better results through lower inflation pressures, and we may find that case fatality rates have improved since the study period.

We agree with others ${ }^{23}$ that the risk of inadvertent premature delivery and iatrogenic RDS will be minimised by restricting elective delivery to cases that present clear-cut indications for induction or elective caesarean section and in which functional maturity can be predicted with near-certainty. Furthermore, our data suggest that recent innovations in the management of RDS will not necessarily have been reflected in a measurable decline in case fatality. Complications of CPAP and the manner in which it is applied are clearly critical additional elements in the cost-benefit ratio.

We are grateful to Professor A C Turnbull and Professor H Campbell for helpful advice; Mrs Wynne Hockings for typing the manuscript; Robert Newcombe for statistical help; all the staff of the Cardiff Births Survey; and Joan Evans and Dr Michael George for supplying data from Hospital Activity Analysis.

Requests for reprints should be addressed to: Dr Iain Chalmers, National Perinatal Epidemiology Unit, The Research Institute, Churchill Hospital, Oxford 0X3 7LJ.

\section{References}

1 Fanconi, A, et al, Schweizerische medizinische Wochenschrift, 1976, 106, 1426.

${ }^{2}$ Farrell, P M, and Wood, R E, Pediatrics, 1976, 58, 167.

${ }^{3}$ Gluck, L, et al, American fournal of Obstetrics and Gynecology, 1971, 109, 440.

${ }^{4}$ Bhagwanani, S G, Fahmy, D, and Turnbull, A C, Lancet, 1972, 1, 159.

5 Howie, R N, and Liggins, G C, in Pre-term Labour, ed A B M Anderson et al, $\mathrm{p} 281$. London, Royal College of Obstetricians and Gynaecologists, 1978 .

${ }^{6}$ Gregory, G A, et al, New England fournal of Medicine, 1971, 284, 1333.

${ }^{7}$ Hjalmarson, O, Epidemiology of neonatal! respiratory disorders. Paper presented at 6 th European Congress of Perinatal Medicine, Vienna, 29 August to 1 September 1978

${ }^{8}$ Reed, D M, Bakketeig, L S, and Nugent, R P, American fournal of Epidemiology, 1978, 107, 299.

${ }^{9}$ Pinkerton, J H M, Martin, D H, and Thompson, W, Lancet, 1975, 1, 197.

10 Goldenberg, R L, and Nelson, K, American fournal of Obstetrics and Gynecology, 1975, 123, 617.

${ }^{11} \mathrm{Hack}, \mathrm{M}$, et al, American fournal of Obstetrics and Gynecology, 1976, 126, 43.

${ }^{12}$ Maisels, J M, et al, Fournal of the American Medical Association, 1977, 238, 2036.

${ }_{13}$ Newcombe, R G, and Chalmers, I, British Medical fournal, 1977, 2, 925.

14 British Medical fournal, 1976, 1, 1553.

15 Chalmers, I, et al, British Medical fournal, 1976, 1, 735.

16 Turnbull, A C, in Benefits and Hazards of the New Obstetrics. Clinics in Developmental Medicine, No 64, ed T Chard and M P M Richards. London, William Heinemann Medical Books, 1977.

17 Pearson, J F, in Current Status of Fetal Heart Rate Monitoring and Ultrasound in Obstetrics, ed R W Beard and S Campbell, p 101. London, Royal College of Obstetricians and Gynaecologists, 1978.

18 Richards, M P M, and Robertson, N R C, in Early Separation and Special Care Nurseries. Clinics in Developmental Medicine, ed F S W Brimblecombe and M P M Richards. London, William Heinemann Medical Books. In press.

19 Haverkamp, A D, et al, American fournal of Obstetrics and Gynecology, $1976,125,310$.

${ }^{20}$ Chalmers, I, Randomised controlled trials of intrapartum fetal monitoring, 1973-7. Paper presented at 6th European Congress of Perinatal Medicine, Vienna, 29 August to 1 September 1978.

${ }^{21}$ Roberton, N R C, Fournal of the Royal College of Physicians, 1977, 11, 389.

${ }^{22}$ Allen, L P, et al, Archives of Disease in Childhood, 1977, 52, 373.

${ }^{23}$ fournal of the American Medical Association, 1977, 238, 2060.

(Accepted 18 August 1978) 